\title{
In vitro production of plant material from fructans- producing species
}

\begin{abstract}
The objective of this work was to obtain plant material in vitro from different fructan producing species. Mother plants of Dahlia australis, Dahlia cordifolia, onion (Allium cepa), asparagus (Asparagus officinalis) and dahlia were used. The disinfection protocol was established for the in vitro establishment of each species. The plants of dahlia and those obtained by seeds were micropropagated with axillary buds as explants. The Dahlia australis were the most easily multiplied by obtaining 4.5 shoots per explant, this being the highest average. The explants of all the species used were cultivated in the culture medium Murashige and Skoog (MS) and subjected to different combinations of plant growth regulators 2,4-D and BAP, at different levels, for the induction of callu and its establishment in suspension. The explants of onion and dahlia, callus formation was not obtained, in the case of asparagus, callus formation was observed in concentrations of $2 \mathrm{mg} / \mathrm{L}$ of $2,4-\mathrm{D}$ and $1.5 \mathrm{mg} / \mathrm{L}$ of BAP, being observed higher biomass in the first and its cell culture was established in suspension at $104 \mathrm{rpm}$, at $23 \pm 3^{\circ} \mathrm{C}$ and photoperiod of $12 \mathrm{~h} \mathrm{light} 12 \mathrm{~h}$ dark. Case of asparagus if it was observed in concentrations of $2 \mathrm{mg} / \mathrm{L}$ of $2,4-\mathrm{D}$ and $1.5 \mathrm{mg} / \mathrm{L}$ of BAP, being observed higher biomass in the first and its cell culture was established in suspension at $104 \mathrm{rpm}$, at $23 \pm 3^{\circ} \mathrm{C}$.
\end{abstract}

Keywords: callus, fructans, dahlia, onion, asparagus
Volume 3 Issue 3 - 2018

\section{Claudia Del Rosario Sánchez-Madrid, Sergio \\ Zavala-Castillo, Margarita Ivonne Garrido- Gutiérrez}

Unidad Interdisciplinaria de Ingeniería Campus, Zacatecas of the National Polytechnic Institute, Mexico

\section{Correspondence: Margarita Ivonne Garrido-Gutiérrez, Unidad Interdisciplinaria de Ingeniería Campus, Zacatecas of the National Polytechnic Institute, Blvd. del Bote S/N Cerro del Gato Ejido La Escondida, Col. Ciudad Administrativa 98160 Zacatecas, Zac, Mexico, Email maguigarrido@yahoo.com}

Received: December 22, 2017 | Published: July 10, 2018

\section{Abbreviations: IAA, indoleacetic acid; BAP, Method benzylaminopurine; ANA, naphthaleneacetic acid; BAP,} benzylaminopurine

\section{Introduction}

Fructans are food ingredients with various health and industrial benefits, so their use is growing. ${ }^{1,2}$ Their chemical structure makes them metabolizable sugars only for colon microorganisms, making them excellent prebiotics and also, for its sweet taste, as a substitute for sucrose. The obtaining of this type of compounds at the industrial level is still limited to only some plants whose cultivation is not done in México and is carried out in a traditional way. There is special interest in agaves since they are known for their content in fructans, however their cultivation involves long periods and remains difficult in situ and in vitro. However, there are other plants that contain these compounds ${ }^{3}$ that can be explored for their production.

Plant biotechnology offers us techniques such as the cultivation of tissues, organs and plant cells that allows us to obtain material under controlled conditions, in relatively short times, reduced spaces and free of pathogens, as well as the rapid multiplication of plants and generation of biomass in any season of the year. ${ }^{4}$ This can help us look for alternatives to obtain other sources of plant material.

In this work, the technique of cultivating plant tissues is used to obtain material from the fructan producing plants Dahlia australis, Dahlia cordifolia, onion (Allium cepa) and asparagus (Asparagus officinalis). Tests are presented for disinfection, in vitro establishment, micropropagation, callus induction and the establishment of cell suspensions in MS medium, using combinations of plant growth regulators, in order to know their feasibility to obtain biomass and that can use new sources to obtain fructans.

\section{Objective}

Cultivate in vitro different plant species producing fructans to obtain plant material.

\section{Plant material}

The seeds of onion and asparagus were from the supplier Hortaflor contained in hermetically sealed envelopes. The seeds and plants of Dahlia australis were acquired in nurseries in the state of Zacatecas, Zac., Mexico and Dahlia cordifolia was donated by the M. in C. José Mejía Muñoz of the Autonomous University of Chapingo.

The viable seeds were identified by the precipitation method in water, where those that were found in the bottom of the container were chosen and those that floated were discarded. Subsequently, the viable seeds were subjected to imbibitions with distilled water for 12 hours.

\section{Disinfection}

Seeds and Dahlia internodes were washed with $200 \mathrm{~mL}$ tap water and $5 \mathrm{~mL}$ detergent Axion, followed by rinsing in $70 \%$ ethanol for one minute to continue with disinfection whit chlorine. After this step we worked on a laminar flow hood where they underwent different treatments for disinfection with commercial chlorine Cloralex (sodium hypochlorite 6\%) at different dilutions and times in light and continuous agitation (Table $1 \&$ Table 2). After the disinfection time, they were rinsed four times with $100 \mathrm{~mL}$ sterile distilled water for 1 minute.

Table I Treatments for seed disinfection

\begin{tabular}{lll} 
Treatment & $\begin{array}{l}\text { Disinfection } \\
\text { time }\end{array}$ & $\begin{array}{l}\text { Dilution of } \\
\text { commercial Chlorine }\end{array}$ \\
sl & 10 minutes & $10 \%$ \\
s2 & 30 minutes & $10 \%$ \\
s3 & 20 minutes & $20 \%$ \\
\hline
\end{tabular}


Table 2 Treatments for disinfection of dahlia

\begin{tabular}{lll}
\hline Treatment & $\begin{array}{l}\text { Disinfection } \\
\text { time }\end{array}$ & $\begin{array}{l}\text { Dilution of } \\
\text { commercial Chlorine }\end{array}$ \\
dl & 20 minutes & $10 \%$ \\
d2 & 30 minutes & $15 \%$
\end{tabular}

\section{In vitro establishment}

The seeds and explants of the different plant species were cultured in semi-solid medium with the complete salts of MS medium (Murashige and Skoog, SIGMA-ALDRICH, St. Louis, CO, USA) medium and supplemented with thiamine $(0.1 \mathrm{mg} / \mathrm{L})$, nicotinic acid, pyridoxine $\mathrm{HCl}(0.5 \mathrm{mg} / \mathrm{L})$, commercial sucrose $(30 \mathrm{~g} / \mathrm{L})$ and solidified with phytagel $(2 \mathrm{~g} / \mathrm{L})$. Its incubation was in artificial culture conditions with white light lamps of 1200 Lumen (Philips T2 18W), in a photoperiod of $16 \mathrm{~h}$ light $8 \mathrm{~h}$ of darkness at $23^{\circ} \mathrm{C} \pm 5^{\circ} \mathrm{C}$. The seedlings that were generated in vitro from seeds were used to obtain new explants of approximately $3 \mathrm{~cm}$ long, for the seedlings from the onion plants, leaves were used, and for asparagus plants, axillary buds were used. In the case of new dahlia explants, axillary buds were also used.

\section{Callus induction}

The explants of all the species were cultivated in MS liquid medium with different treatments. The combinations of the plant growth regulators (RCV) 2,4-dichlorophenoxyacetic acid (2,4-D) and benzylaminopurine (BAP) are shown in Table 3. The experiment was done both in light circumstance and in the dark.

Table 3 Combinations of plant growth regulators

\begin{tabular}{|c|c|c|}
\hline Treatment* & 2,4-D (mg/L) & BAP (mg/L) \\
\hline$c 3$ & 2 & 1.5 \\
\hline c2 & 3 & 0.3 \\
\hline $\mathrm{cl}$ & 3 & I \\
\hline
\end{tabular}

*Half of the experimental units of each treatment were subjected to darkness.

\section{Cell culture in suspension}

Cell suspensions were initiated from the friable callus obtained. They were established from the treatments that presented the best response in semi-solid medium, using a volume of $25 \mathrm{ml}$ of the same medium but without the addition of phytagel, that is, in liquid medium. Subcultures were made every 15 days under sterile conditions and were maintained in an incubator with continuous agitation at 104rpm, under white light illumination of 1200 Lumens (Philips T2 18W), at $23^{\circ} \mathrm{C} \pm 3^{\circ} \mathrm{C}$ and with a long photoperiod of $16 \mathrm{~h}$ light and $8 \mathrm{~h}$ dark.

\section{Design of experiments}

In the case of seeds, each treatment (culture flask) consisted of 5 explants per species, for the specific case of the Dahlia explants each treatment consisted of 4 explants.

For the micro propagation and callus induction, the new explants obtained in vitro from the first cultures were used; for each treatment (culture flask), 4 explants were used.

The treatments were performed in triplicate and each explant was considered an experimental unit.

\section{Results}

\section{Disinfection}

The efficiency of each disinfection treatment for each species was evaluated, considering the number of contaminated and noncontaminated seeds with respect to the total). Likewise, it was observed that $\mathrm{s} 3$ treatment was efficient for all seed species (Figure 1-4), since $100 \%$ of experimental units were obtained without contamination. This treatment was the longest time of immersion and concentration of sodium hypochlorite, that is, $20 \%$ of sodium hypochlorite for $20 \mathrm{~min}$. On the other hand, the results show that at lower concentration and contact time with the disinfectant agent, the plant materials used showed greater contamination (analyze the treatment s1 in Figures $1-4)$.

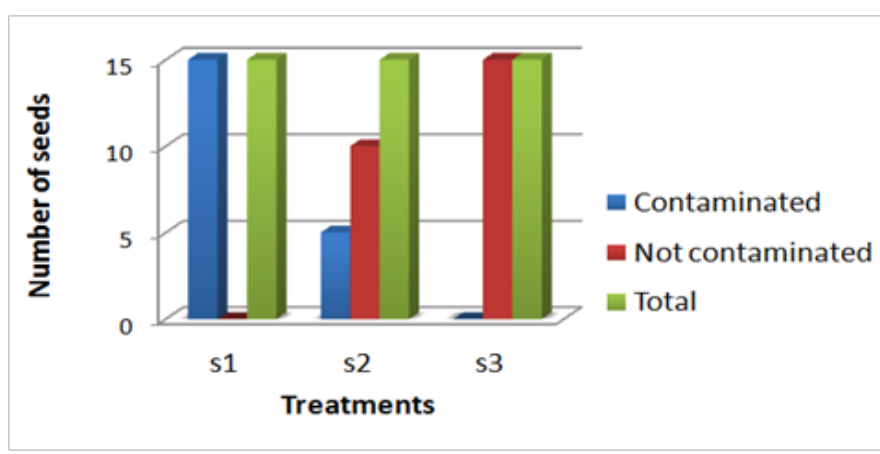

Figure I Disinfection of dahlia seeds.

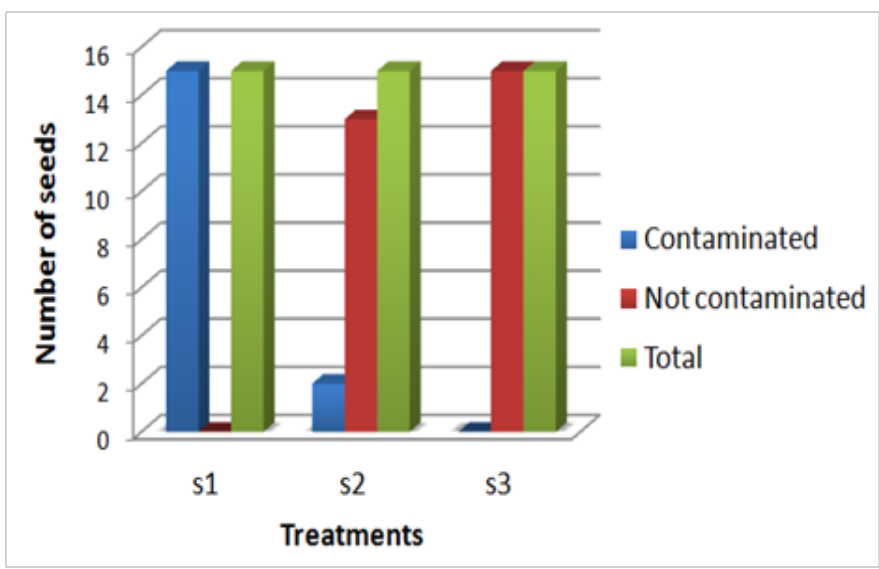

Figure 2 Disinfection of asparagus sedes.

The results obtained for the disinfection of the dahlia explants were different among the different species. Figure 4 shows that Dahlia cordifolia had a higher number of contaminated explants compared with Dahlia australis. In addition, it was evidenced that the d2 treatment eliminated superficial contamination of the plant tissues in both dahlia species, since fewer contaminated experimental units were observed (Figure 4) and $83.33 \%$ were non-contaminated.

\section{In vitro establishment}

Seeds

The seeds planted in vitro presented different percentages of germination according to the species (Table 4). Those of dahlia did not germinate those of the rest of the species that did it, developed seedlings in relatively short times. In the case of asparagus, seedlings 
were observed in two week of $10 \mathrm{~cm}$ in height, compared to the onion which took up to three weeks to reach the same height (Figure 5).

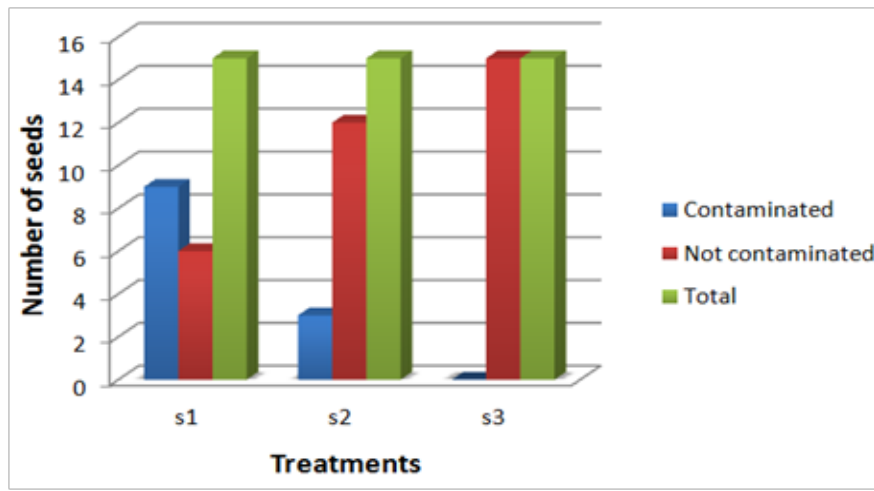

Figure 3 Disinfection of onion sedes.

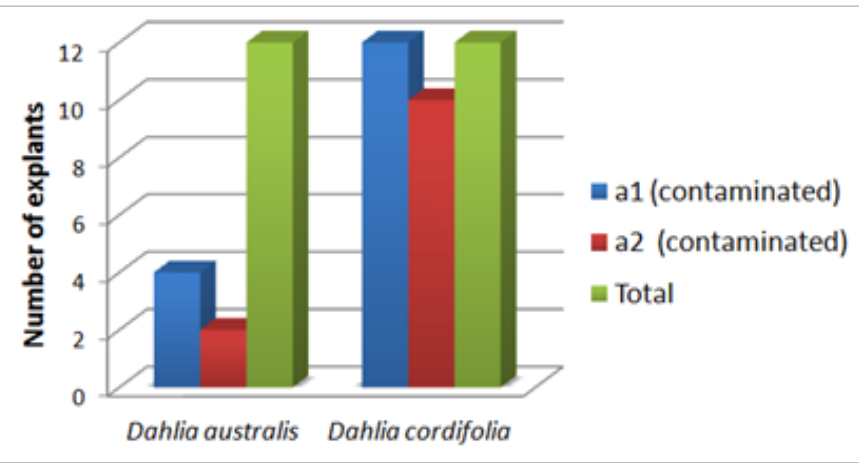

Figure 4 Disinfection of Dahlia australis and D. cordifolia. The comparison between the disinfection treatments $\mathrm{dl}$ and $\mathrm{d} 2$ (table 2 ) and the number of contaminated explants is shown.
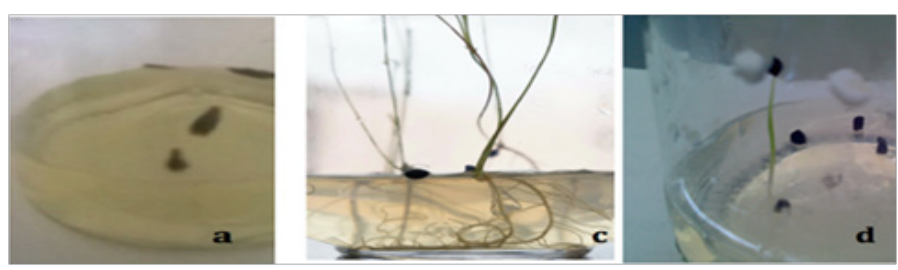

Figure 5 Seed germination in vitro in semi-solid MS medium after one week of incubation. (a) Dahlia, (c) Asparagus and (d) Onion.

All the seedlings developed in vitro had roots that were covering the entire culture medium. The seedlings grew until the glass bottles allowed it and were used as donors of explants.

Table 4 Germination percentages of seeds grown in vitro

\begin{tabular}{lll}
\multicolumn{2}{l}{ Seed germination in vitro } \\
\hline Plant & Germination percentage & Germination time \\
\hline Asparagus & $90 \%$ & 7 days \\
Dahlia & $0 \%$ & Unanswered \\
Onion & $90 \%$ & 5 days \\
\hline
\end{tabular}

\section{Mother plants of Dahlia australis and Dahlia cordifolia}

Since no seedlings were obtained by seed germination to obtain dahlia explants, two mother plants of two species, Dahlia australis and
Dahlia cordifolia, were used. For the case of $D$. cordifolia, meristem explants were obtained, and for both, axillary buds were used.

To isolate the meristems (Figure 6) a motic stereomicroscope BA310 was used and these were cultured in semi-solid MS medium. With this technique healthy plants were obtained but without root formation. Subcultures were necessary for their accommodation and adequate growth. Its growth was observed for 40 weeks before sub culturing (Figure 7). It was incubated up to 5months without presenting microbial contamination.

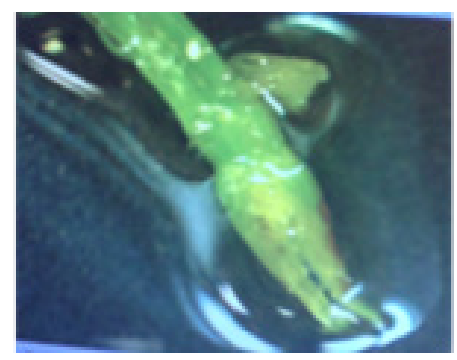

Figure 6 Dahlia cordifolia meristem after dissection. Stereoscopic microscope image with the objective of increasing Ix.
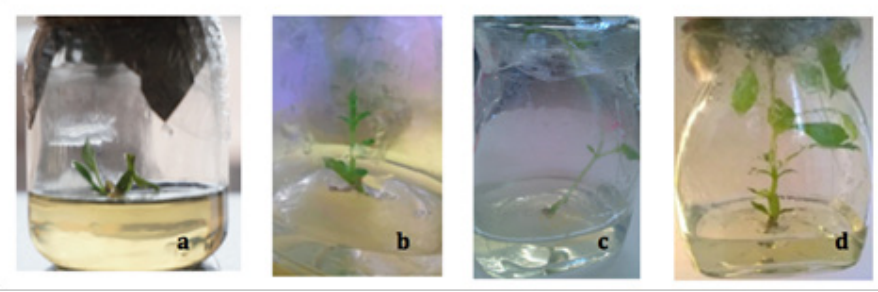

Figure 7 In vitro seedling growth obtained from Dahlia cordifolia meristem. (a) one week of incubation, (b) two weeks of incubation, (c) 3 weeks of incubation and (d) 4 weeks of incubation.

In the explants of Dahlia cordifolia when axillary buds were used, shoot development was observed, first stem growth and then small leaves for Dahlia australis, under the same growing conditions as $D$. cordifolia, new buds with higher growth were obtained, had larger leaves, in greater quantity and with a more intense greenness in comparison with $D$. cordifolia (Figure 8). The new shoots presented a favourable growth in the measure that the bottle of culture allowed it. These outbreaks were used as donors of explants to continue with the micro propagation. It was evident that the most efficient species was Dahlia australis (Figure 8).
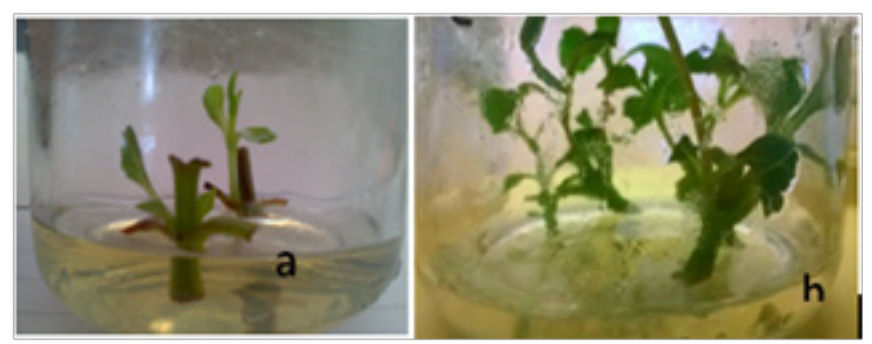

Figure 8 Development of shoots in explants of axillary buds of Dahlia cordifolia (a) and Dahlia australis (b) after one week of incubation.

\section{Multiplication of plant material}

The micro propagation of dahlia was carried out from the developed buds of the axillary buds. For Dahlia cordifolia, the 
explants that were cultivated in semi-solid MS medium did not survive, they were very thin, so they were cultivated in liquid medium (Figure 9). Here, growth and depletion of nutrients from the culture medium after 8 weeks of culture was observed (Figure 9). From the results obtained it is observed that this technique was the best option for the micro propagation of this species, also considering that less medium is required and there is greater availability of nutrients for the plant, however care is required since if the explant touches the wall of the test tube the explant may die (Figure 9).

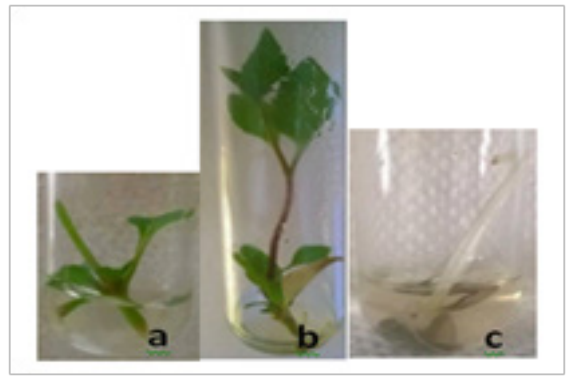

Figure 9 Development of axillary buds of Dahlia cordifolia in liquid medium, at the start of incubation (a), after 8 days (b) and its death by the conditions of the culture vessel.

In the case of Dahlia australis, the micro propagation was efficient in semi-solid MS medium using the axillary buds as explants. New shoots were obtained after 8days of incubation and from these new explants were generated that were grown for the multiplication of the plant material. To make the subcultures it was necessary to dissect the leaves and part of the petiole so that the explants were less heavy. These shoots were used as donors of explants for the induction of callus. The new explants when cultivated presented root formation, without the need to add plant growth regulators (Figure 10). The Dahlia australis presented better growth characteristics to continue with its multiplication due to the vigor of the obtained seedlings and the root formation in comparison with the Dahlia cordifolia.

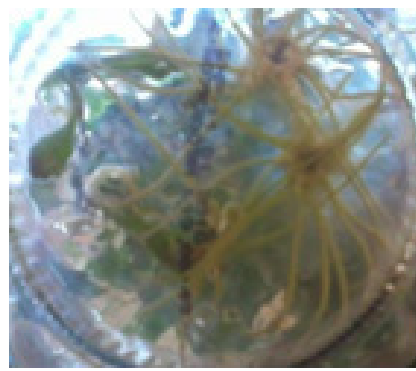

Figure I0 Root growths in young explants of Dahlia australis.

The multiplication of the onion was not efficient, the explants showed no growth. Asparagus presented new buds from the axillary buds and a good growth response was observed in semi-solid MS medium. The number of buds obtained by each species is concentrated in Figure 11

\section{Callus induction}

The specie with the best response to the three treatments proposed in Table 3 was asparagus, since there was callus formation in all the explants (Figure 12a \& b), with c3 being the one that showed the best response (Table 5). The onion and dahlia explants showed no callus formation

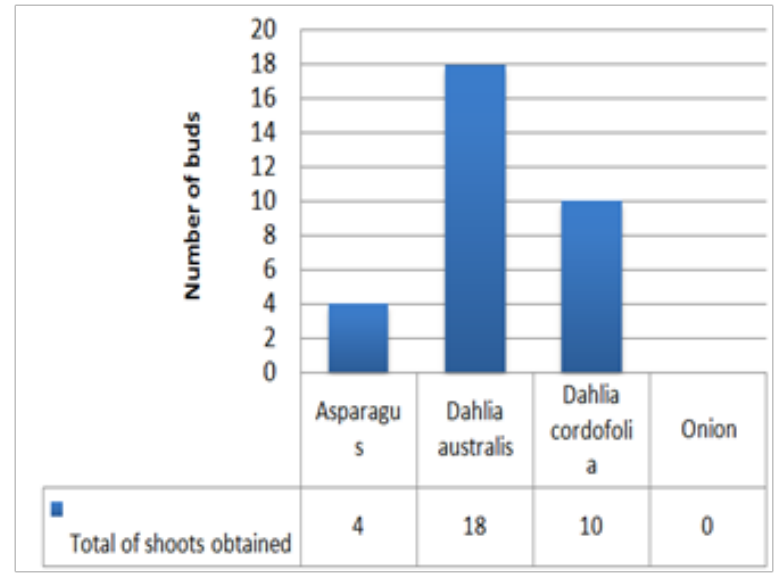

Figure I I Number of buds obtained by species.

\section{Cell culture in suspension}

The dissection was performed to fragment the friable calli and establish the cells in suspension (Figure 12c-f). Once the biomass increased, they were subculture to fresh culture medium for expansion and maintenance. In the case of asparagus, greater growth and greenery were observed (Figure $12 \mathrm{e} \& \mathrm{f}$ ). It should be mentioned that antioxidants were not used. There is little information on the establishment of cell suspensions of these species and in the experimental conditions used they present a good response, so they can be an option to obtain biomass of these species in a short time.
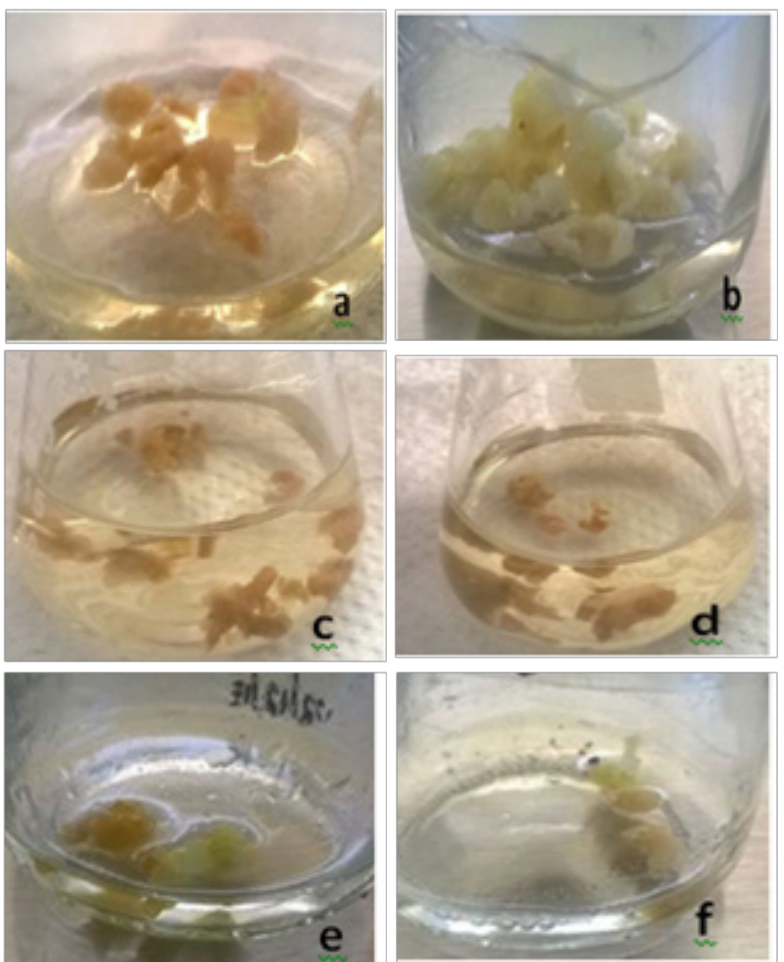

Figure I 2 Growth of callus of broccoli (a) and asparagus (b) in c3 treatment at three weeks of incubation in semi-solid medium and its cell suspensions (c and $\mathrm{d}$ broccoli; $\mathrm{e}$ and $\mathrm{f}$ asparagus) in $25 \mathrm{ml}$ of liquid medium. 
Table 5 Percentage of viable callus in the plants used. See table 3 for meaning of $\mathrm{cl}-3$

\begin{tabular}{llll}
\hline Treatment & Asparagus & Onion & Dahlia \\
\hline cl & $50 \%$ & $0 \%$ & $0 \%$ \\
c2 & $100 \%$ & $0 \%$ & $0 \%$ \\
c3 & $100 \%$ & $0 \%$ & $0 \%$ \\
\hline
\end{tabular}

\section{Discussion}

In this work the experimental conditions were investigated to cultivate in vitro to the plants of onion, asparagus and dahlia, that propagate with traditional practices of agriculture, to be able to establish a method with which sufficient biomass is generated for a later obtaining of fructans It began with the determination of the exposure time and the concentration of the highly oxidizing agent that was used, sodium hypochlorite. The levels and the extension of the contact time that this was with the plant tissues depended on the resistance structures naturally contained in them, which allowed them to remain viable after the treatments tested. Reason why it was not possible to eliminate surface contamination of the dahlia plants (Figure 4), since the susceptibility to the disinfecting agent was considerable in the peripheral cells to the axillary buds. On the other hand, in the seeds of all the plants worked, $100 \%$ elimination of surface contamination was achieved with the disinfection treatments (Figure 1-4), which shows the protection provided by their testa to the embryo of the seeds before the oxidizing power of the disinfectant. Notwithstanding the known toxicity of sodium hypochlorite contained in the commercial chlorine that was used, it is a resource that is obtained easily, because there are other even more toxic disinfectants with greater difficulty in obtaining them. ${ }^{5}$ However, sodium hypochlorite $(\mathrm{NaOCl})$ from $0.6 \%$ to $5 \%$ contained in products for domestic use is very used. ${ }^{6-8}$ Different authors have reported the use of the commercial agent used in this experiment (Cloralex $\square$ ) in solutions from $15 \%$ to $30 \% \mathrm{v} / \mathrm{v},{ }^{9,10}$ it was decided to make solutions within this range and lower to it, to cause as little damage as possible to the explants and decrease their oxidation.

The combined treatment of choice of viable seeds by the flotation method together with the imbibitions in water resulted in a good mixture to favour the percentage of germination in the plants worked in a reduced time (Table 4). However, for the case of dahlias seeds, it was not like that, the unfavourable results in this species may be due to the fact that they have been reported to lose viability rapidly and have been generally considered as sterile ${ }^{11}$ and this is the reason why axillary buds of a dahlia mother plant were used like buds.

With the results obtained in relation to the number and vigor of the outbreaks originated with the two species tested (Figure 10) (Figure 11) it is clear that there is a differential response between them. This response is related to the phenotype of the plants, that is, $D$. codifolia is a plant with stems and leaf area characteristically thin and reduced, respectively. And in vitro culture showed a lower number of shoots. In comparison, $D$. australis is a plant with stems of greater thickness, prominent foliage and the in vitro response was superior to $D$. codifolia. Due to the above, it is possible to make the choice of mother plants donating explants according to the vigor they show. This remains to be confirmed with research with more species of dahlias. It has been reported that the effect of gibberellic acid on the in vitro multiplication of Dahlia spp. and the concentration of $1 \mathrm{mg} .1-1$ in the culture medium, caused an increase in the height of the plant, as well as the number of segments/explant, ${ }^{12}$ also De Klerk \& Brugge., ${ }^{13}$ reported that growth of dahlia (Dahlia hybrida) shoots in vitro was ca. 4 times faster in liquid medium than on solidified medium, in liquid standard medium (3\% sucrose, macroelements according to DriverKuniyuki Walnut medium, microelements according to MurashigeSkoog medium, 0.44M benzylaminopurine).

In relation to the negative results in the micropropagation of onion plants, they were possibly due to the type of explant used, which was not adequate for the species. The propagation of this has been reported using meristems and flowers as explants. ${ }^{14}$ The results obtained with respect to the induction of callus were encouraging with asparagus (Table 5) and were corroborated when establishing their cultures in suspension with them (Figure $12 \mathrm{c}-\mathrm{f}$ ). For dahlia and onion, possibly the lack of callus development is due to the type of growth regulator used and the type of explants. Other authors report callus response in these species using naphthaleneacetic acid (ANA) and BAP and with onion explants such as meristems and for dahlia cotyledon leaves and hypocotyl explants, ${ }^{14,15}$ has also been reported the obtaining of Dahlia sp. calli with stem explants with $0.5 \mathrm{mg} / \mathrm{L}$ benzylaminopurine (BAP) and $1 \mathrm{mg} / \mathrm{L}$ indoleacetic acid (IAA) and calli suspension cultures were achieved with stirring at $88 \mathrm{rpm}$ and the same plant growth regulators. Combinations that were obtained for calli formation. ${ }^{16,17}$

No significant differences were observed in the callus induction in the dark, thanks to this, the treatments were continued under natural light conditions, however the growth rate and the friability characteristics depend on each species, the hormonal balance and others factors.

\section{Conclusion}

a. It was possible to establish and multiply in vitro the fructanproducing plants of asparagus (Asparagus officinalis), onion (Allium cepa) and dahlia (Dahlia australis and D. codifolia).

b. The protocol for disinfection was established according to the needs of the managed species. For Dahlia australis was the treatment $\mathrm{d} 2$, for the seeds of asparagus (Asparagus officinalis) and onion (Allium cepa) was the $\mathrm{s} 3$.

c. The in vitro culture was established and seedlings of the species of dahlia, asparagus (Asparagus officinalis) and onion (Allium сера) were obtained. The seeds of dahlia did not germinate.

d. Dahlia was obtained free of contamination when the explant was meristem.

e. The amount of plant material of Dahlia australis, asparagus (Asparagus officinalis) was multiplied. The latter one developed on average 3days faster than the others.

f. Dahlia australis obtained the highest average number of shoots, 4.5 shoots per explant and showed great root formation, followed by asparagus.

g. Production of asparagus (Asparagus officinalis) was induced with the treatment $(2 \mathrm{mg} / \mathrm{L}$ of $2,4-\mathrm{D}$ and $1.5 \mathrm{mg} / \mathrm{L}$ of BAP).

h. Cellular suspensions of callus obtained from asparagus (Asparagus officinalis) were obtained in treatment $\mathrm{c} 3$, greater viability was observed in the case of asparagus. 


\section{Acknowledgements}

The authors thank to the Interdisciplinary Professional Unit of Engineering Campus Zacatecas for providing facilities and equipment.

\section{Conflict of interests}

The author declares there is no conflict of interest.

\section{References}

1. Zuleta A, Araya H. Carbohydrates as functional ingredients. In: M Luz, A León, editors. Nutritional and healthy aspects of bread products Chile. University of Valparaíso, 2009. p. 61-64.

2. Hernández-Carranza P, Jiménez-Munguía M. Functional properties and industrial applications of fructo-oligosaccharides. Selected Topics of Food Engineering. 2010;1-8.

3. Madrigal L, Sangronis E. Inulin and derivatives as key ingredients in functional foods [electronic version]. Arch Latinoam Nutr. 2007:57(4):387-396.

4. Abdelnour Esquivel A, Vicent Escalant J. Basic Concepts of Plant Yew Cultivation. Mexico, D.F: Inter-American Documentation and Agricultural Information; 1994.

5. Roca WM, Nolt B, Mafla G. Elimination of viruses and propagation of clones in cassava (Manihot esculenta Crantz). In: Roca WM, Mroginski LA, editors. Cultivation of fabrics in agriculture: fundamentals and applications. CIAT, Cali, Colombia; 1991.

6. Segretín ME. (2007). Los cultivos celulares y sus aplicaciones II (cultivos de células vegetales). Consejo argentino para la información y el desarrollo de la biotecnología.

7. Abdelnour-Esquivel A, Escalant J. Conceptos basicos del cultivo de tejidos vegetales. Turrialba, Costa Rica: CATIE; 1994.
8. Robert ML, Herrera JL. Contreras F, et al. In vitro propagation if Agave fourcroydes Lem. (Henequen). Plant Cell, Tissue and Organ Culture. 1987;8(1):37-48.

9. Domingez-Rosales M, Gonzáles-Jiménez M, Rosales-Gómez C, et al. El cultivo in vitro como herramienta para el aprovechamiento, mejoramiento y conservación de especies del género Agave. Investigación y ciencia de la universidad autónoma de Aguascalientes. 2008;16(41):53-57.

10. Flores Morales A, Castañeda Hidalgo ESF, Sánchez Pérez F, et al Mecanismos de conservación y uso del maguey pulquero Agave salmiana en el Altiplano mexicano. Recuperado el, de Sociedad Mexicana de Agricultura Sostenible A.C. 2016.

11. Álvarez-Pinto M. Dahlia Agrotécnia. In: Floriculture. Havana: Editorial People and Education. 1989;397-434.

12. Jiménez Mariña L, Fonseca Arias M, Infante Fonseca S, et al. Efecto del ácido giberélico en la multiplicación in vitro de Dahllia spp. Revisto Granma Ciencia. 2013;12(1).

13. De Klerk GJ, Brugge J. Micropropagation of dahlia in static liquid medium using slow-release tools of medium ingredients. Scientia Horticulturae. 2011;127(4):542-547.

14. Cárdenas A, Espinoza R. Practical guide to in vitro cultivation of plant species. Salesian Polytechnic University. 2014;32-33.

15. Muhamma Usma F. In vitro shoot regeneration from cotyledon and hypocotyl explants of Dalhia cultivars. Pak J Agri Sci. 2007;2(44):312316

16. Garrido Gutiérrez MI. Establishment in vitro shoots and callus Dahlia sp. for later use to obtained insulin. Mexican Journal of Biotechnology. 2017;2(2):130-141.

17. Santacruz Ruvalcaba F, Gutiérrez Pulido H, Rodríguez Garay B. Efficient in vitro propagation of Agave parrasana Berger. Khnver Academic Publishers. 1999;56(3):163-167. 